\title{
Body mass index and motor coordination: Non-linear relationships in children $6-10$ years
}

\author{
V. P. Lopes ${ }^{1}$ (1) | R. M. Malina ${ }^{2}$ | J. A. R. Maia ${ }^{3}$ | L. P. Rodrigues ${ }^{4}$
}

${ }^{1}$ Research Center in Sports Sciences, Health Sciences and Human Development (CIDESD), Sport Science Department of Polytechnic Institute of Bragança, Bragança, Portugal

${ }^{2}$ Department of Kinesiology and Health Education, University of Texas at Austin, Austin, TX, US

${ }^{3}$ Faculty of Sport, University of Porto, Porto, Portugal

${ }^{4}$ Escola Superior Desporto e Lazer de Melgaço, Instituto Politécnico de Viana do Castelo, and CIDESD, Viana do Castelo, Portugal

Correspondence

Vitor P. Lopes, School of Education of Polytechnic Institute of Bragança, Campus de Santa Apolónia, Bragança 5301-856, Portugal. Email:vplopes@ipb.pt

\section{Funding information}

Portuguese Foundation for Science and Technology, Grant/Award Numbers: DTP/04045/ 2013, POCI-01-0145-FEDER-006969, UID/ DTP/00617/2013 and POCI-01-0145FEDER-006969; NORTE 2020, Grant/Award Number: NORTE-01-0145-FEDER-000016

\begin{abstract}
Background: Given the concern for health-related consequences of an elevated body mass index (BMI; obesity), the potential consequences of a low BMI in children are often overlooked. The purpose was to evaluate the relationship between the BMI across its entire spectrum and motor coordination (MC) in children 6-10 years.

Methods: Height, weight, and MC (Körperkoordinationstest für Kinder, KTK test battery) were measured in 1,912 boys and 1,826 girls of 6-10 years of age. BMI $\left(\mathrm{kg} / \mathrm{m}^{2}\right)$ was calculated. KTK scores for each of the four tests were also converted to a motor quotient (MQ). One-way ANOVA was used to test differences in the BMI, individual test items, and MQ among boys and girls within age groups. Sex-specific quadratic regressions of individual KTK items and the MQ on the BMI were calculated. Girls and boys were also classified into four weight status groups using International Obesity Task Force criteria: thin, normal, overweight, and obese. Differences in specific test items and MQ between weight status groups were evaluated by age group in each sex.
\end{abstract}

Results: Thirty-one percent of the sample was overweight or obese, whereas $5 \%$ was thin. On average, normal weight children had the highest $\mathrm{MQ}$ in both sexes across the age range with few exceptions. Overweight/obese children had a lower $\mathrm{MQ}$ than normal weight and thin children. The quadratic regression lines generally presented an inverted parabolic relationship between the $\mathrm{BMI}$ and $\mathrm{MC}$ and suggested a decrease in $\mathrm{MC}$ with an increase in the BMI.

Conclusion: In general, BMI shows a curvilinear, inverted parabolic relationship with $\mathrm{MC}$ in children 6-10 years.

\section{KEYWORDS}

childhood, motor performance, motor proficiency, obesity, thinness, weight status

\section{1 | INTRODUCTION}

The increasing prevalence of overweight/obesity among children and adolescents is a major health concern with an estimated prevalence of $24 \%$ in boys and girls in developed countries in 2013 (World Health Organization [WHO], 2016). Conversely, corresponding estimates in developing countries range from $8 \%$ to $13 \%$ in both boys and girls ( $\mathrm{Ng}$ et al., 2014). Although the prevalence of obesity appears to be reaching a plateau in some countries, absolute numbers of overweight and obese children have increased more in low and middle income countries than in high-income ones (WHO, 2016).
The use of the body mass index (BMI) to specify overweight and obesity is often referred to in the context of excessive fatness. This is naturally relevant to motor performance and physical fitness, because excess fatness generally exerts a negative influence on tasks which require the movement or projection of the body through space, as in runs and jumps (Malina, 1975). Available data indicate a negative relationship between the $\mathrm{BMI}$ and fundamental motor skills (Duncan, Bryant, \& Stodden, 2016) and motor coordination (MC; Lopes, Stodden, Bianchi, Maia, \& Rodrigues, 2012) in children. Studies have also shown that children with a higher level of $M C$ tend to have lower BMls (Martins et al., 2010), whereas children identified as clumsy have a higher level of relative fatness (Hay, Hawes, \& Faught, 
2004). Negative associations between the BMI and indicators of fitness have also been noted (He et al., 2011; Mcgavock, Torrance, Mcguire, Wozny, \& Lewanczuk, 2009). A variety of studies have addressed relationships between the BMI and motor performance and fitness, but they have generally compared individuals classified as normal weight and overweight/obese, and/or have generally used linear association methods. Results generally show a linear negative relationship between $\mathrm{BMI}$ and fitness, especially when focused on overweight/obese individuals.

Until recently, studies have not ordinarily considered performance and fitness in samples with BMls that span the spectrum from thinness through obesity, and only several have considered potential non-linear relationships (Bovet, Auguste, \& Burdette, 2007; Huang \& Malina, 2007; Huang \& Malina, 2010; Sekulić, Zenić, \& Marković, 2005). Observations for a national sample of Taiwanese youth 9-18 years, for example, have generally indicated inverted parabolic relationships between BMI and four fitness tests across age groups in both sexes, although relationships varied among tests (Huang \& Malina, 2010).

Given concern for the health-related consequences of an elevated $\mathrm{BMI}$, the potential consequences of a low BMI for indicators of movement proficiency are often overlooked and highlight the need to consider different aspects of motor performance in children with BMls spanning the spectrum from thin to obese. In this context, the purpose of this study is to evaluate the non-linear relationships between the BMI and MC in children 6-10 years with BMls spanning the spectrum from low (thin) to high (obese). MC was assessed with the Körperkoordinationstest für Kinder (KTK; Body Coordination Test for Children; Kiphard \& Schilling, 1974, 2007). To our knowledge, studies to date have not considered relationships between the BMI and performances on this $M C$ test across the full spectrum of BMI. As suggested in several earlier studies (Huang \& Malina, 2007; Huang \& Malina, 2010; Lopes et al., 2017), a curvilinear relationship expressed in an inverted parabolic form was anticipated, with children with lower and higher BMls showing poorer levels of MC.

\section{2 | METHODS}

\section{1 | Participants}

The study was approved by the ethical committee of the local health authority in the Azores islands, Portugal, and by the institution of the first author. Participants were elementary school children ( $N=3,738$ ), 1,826 girls and 1,912 boys, 6 to 10 years of age, from the Azores islands, Portugal. Written informed consent was obtained from the parents of each child.

The prevalence of overweight/obesity of Azores islands in children is about 30\% (Maia \& lopes, 2007). The Human Development Index for the region was 0.903 in 2013 and was comparable with most European countries.

\section{2 | Field methods}

Data were collected by four teams of teachers who were trained in the methods of measuring height and weight and in administering the $M C$ tests.

\section{Key messages}

- The relationship between the body mass index (BMI) and motor coordination (MC) is variable among tasks.

- The evidence suggested a curvilinear relationship between the $\mathrm{BMI}$ and $\mathrm{MC}-\mathrm{a}$ low weight-for-height and especially a high weight-for-height have the potential to negatively influence on $\mathrm{MC}$.

- Children, especially older children 8-10 years, with intermediate BMls tended to have, on average, better $\mathrm{MC}$ than those with low and high BMI values.

- The relationship between BMI and MC was generally similar in boys and girls.

- Overall, underweight (thin) youth had lower MC scores than normal weight youth, but both generally performed better than overweight/obese youth.

\section{3 | Body size}

Height was measured with an anthropometer to $0.1 \mathrm{~cm}$, and weight was measured with a digital scale (SECA, Hamburg, Germany) to $0.1 \mathrm{~kg}$ using standard procedures. Intraclass correlations based on replicate measurements varied between 0.92 and 0.99 for height and between 0.94 and 0.99 for weight, whereas technical errors of measurement for height varied between $0.20 \mathrm{~cm}$ and $0.91 \mathrm{~cm}$. The BMI $\left(\mathrm{kg} / \mathrm{m}^{2}\right)$ was calculated. Weight status of each child was classified as thin, normal, overweight, or obese using the sex-specific International Obesity Task Force (IOTF) cut-off values for children (Cole, Bellizzi, Flegal, \& Dietz, 2000; Cole, Flegal, Nicholls, \& Jackson, 2007). Although a low BMI is sometimes indicated as underweight, the label thin was recommended by the IOTF (Cole et al., 2007).

\section{4 | Motor coordination}

The KTK (Kiphard \& Schilling, 1974, 2007) includes four items: (a) walking backwards along balance beams of decreasing width $(6.0,4.5$, and $3.0 \mathrm{~cm})$, (b) moving sideways on wooden boards during $20 \mathrm{~s}$, (c) jumping sideways over a slat for $15 \mathrm{~s}$, and (d) hopping over foam obstacles with increasing height in consecutive steps of $5 \mathrm{~cm}$. The raw performance scores for each test item were converted to a standardized score relative to sex- and age-specific reference values for the population upon which the KTK was established (Kiphard \& Schilling, 1974). The sum of standardized scores for the four items provided an overall motor quotient (MQ). Reported reliability coefficients for the KTK ranged from 0.80 to 0.96 for individual tests; the coefficient was 0.97 for the total battery (Kiphard \& Schilling, 1974, 2007). Reliabilities in the present study (intraclass correlations) varied between 0.75 and 0.91 .

\section{5 | Data analysis}

Descriptive statistics for age, the BMI, each coordination test, and the $\mathrm{MQ}$ were calculated. One-way analysis of variance was used to test 
sex differences in the BMI, KTK items, and $M Q$ in single year age groups and to test corresponding differences between single year age groups within each sex.

Sex-specific regressions of each individual test and the MQ on the $\mathrm{BMI}$ were also performed in single year age groups. This was done so as both the BMI and performances on each test increase, on average, with age. Given observations on relationships between fitness items and the BMI in older youth (Huang \& Malina, 2010), a quadratic regression model was used as it permits testing of the expected non-linear relationships. The KTK test item or the $\mathrm{MQ}$ was the dependent variable, whereas the $\mathrm{BMI}$ and $\mathrm{BMI}^{2}$ were the independent variables as follows:

$$
M Q=a+b^{*} B M I+c^{*} B M^{2}
$$

where $\mathrm{a}, \mathrm{b}$, and $\mathrm{c}$ were constant.

Performances on each of the four KTK tests and subsequently the $\mathrm{MQ}$ were calculated for boys and girls in each weight status category (thin, normal, overweight, and obese) by age. The Kruskal-Wallis test was used to evaluate potential differences in the KTK results among weight status groups by age and sex. Significance for all analyses was set at $p \leq .05$.

\section{3 | RESULTS}

Descriptive statistics are summarized by age groups within sex in Table 1. The heights of both boys and girls approximate, on average, the age and sex-specific medians of the WHO (2006) reference. As expected, the BMI increases, in general, with age in boys and girls (boys, $F_{4,1907}=14.1 ; p<.001$; girls, $F_{4,1827}=16.2 ; p<.001$ ).

Performances on each $M C$ test increase also with age in both sexes, but the MQ declines, in general, with age. There is considerable overlap in performance scores for each KTK item between sexes across the age range, but the $\mathrm{MQ}$ is, on average, significantly higher in boys compared with girls. Within each sex, older children tend to have significantly lower MQs than younger children (boys, $F_{4}$, $1907=8.9 ; p<.001 ;$ and girls, $F_{4,1827}=26.0 ; p<.001$ ).

Relationships between the $\mathrm{BMI}$ and each $\mathrm{MC}$ test item in the five age groups of girls and boys based on quadratic regressions are illustrated in Figure 1. The figure also includes the results of the quadratic regression models.

For balancing backwards (Figure 1), the relationship is curvilinear in each age group of girls, whereas a curvilinear relationship is suggested only at 6 and 10 years in boys. In all age groups except 6 years, the quadratic term of the regression equation is lower in boys than in girls and is apparent in a steeper decline in performance with an increasing $\mathrm{BMI}$ in girls than in boys.

A similar curvilinear relationship at all ages in girls and at all ages except 10 years in boys is suggested for jumping laterally (Figure 1). The decline in performance at higher BMIs is generally similar in both sexes.

Curvilinear relationships between performances on the one leg hopping test and the BMI are suggested in both sexes and all age groups except 6 years (Figure 1). The slopes of the decrease in performance with an increase in the $\mathrm{BMI}$ are similar in girls and boys and are especially marked among 10 year old children.

In contrast, relatively slight curvilinear relationships between performances on the shifting platform test and the BMI are suggested in each age group of boys (Figure 1). Trends in girls are more variable; they suggest a linear decline in performance with an increasing BMI in at 7 and 9 years but a curvilinear relationship at 6, 8, and 10 years.

Corresponding quadratic regressions for the $\mathrm{MQ}$ are illustrated in Figure 2. Curvilinear relationships between the $\mathrm{BMI}$ and $\mathrm{MQ}$ are indicated in girls, especially at 10 years. Curvilinear relationships are quite similar in boys at all ages.

Multiple correlations $(R)$ between the BMI and individual KTK items, and the $\mathrm{MQ}$, and the common variance $\left(R^{2}\right)$ based on the quadratic regression model for each item in girls and boys by age group

TABLE 1 Sample sizes and means (M) and standard deviations (SD) for age, height, weight, BMI, individual KTK test items, and the motor quotient by sex and age group

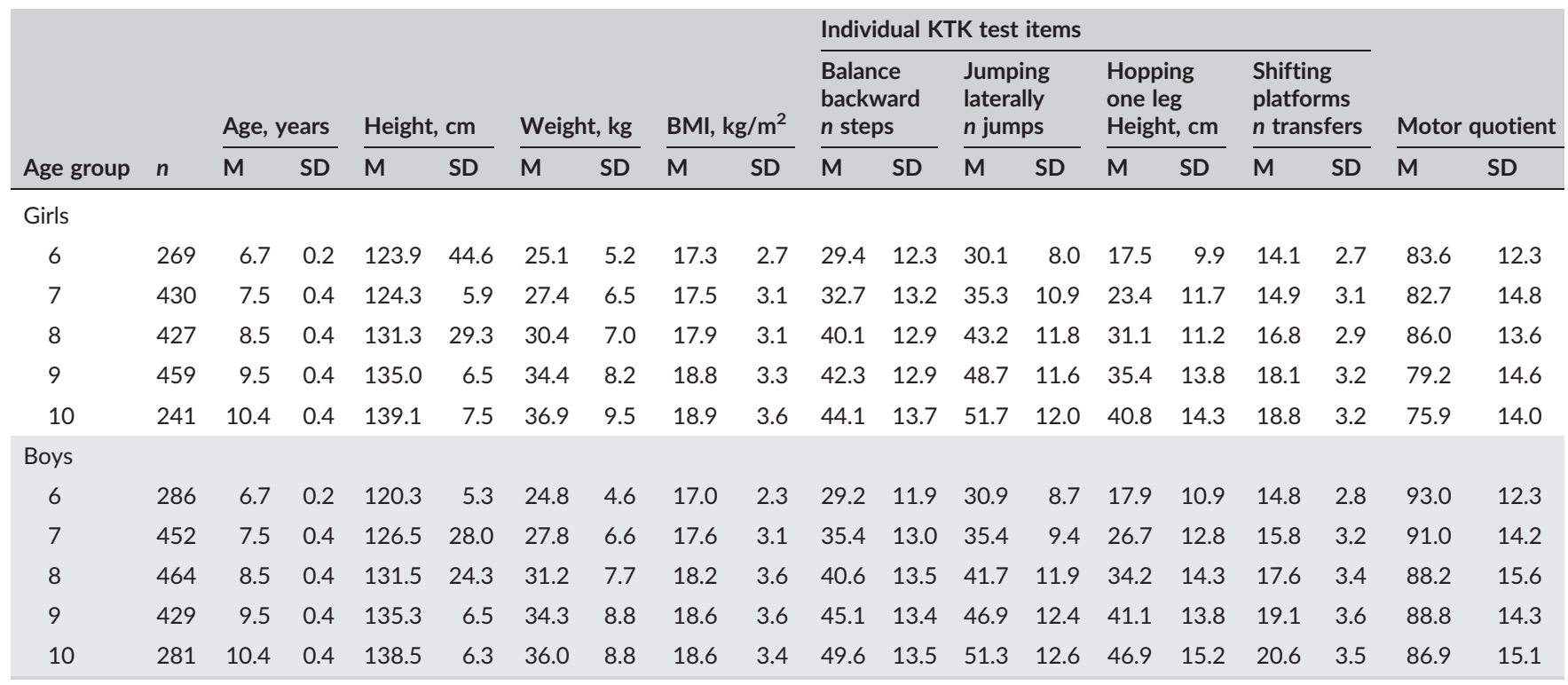

Note. $\mathrm{BMI}=$ body mass index; $\mathrm{KTK}=$ Körperkoordinationstest für Kinder. 

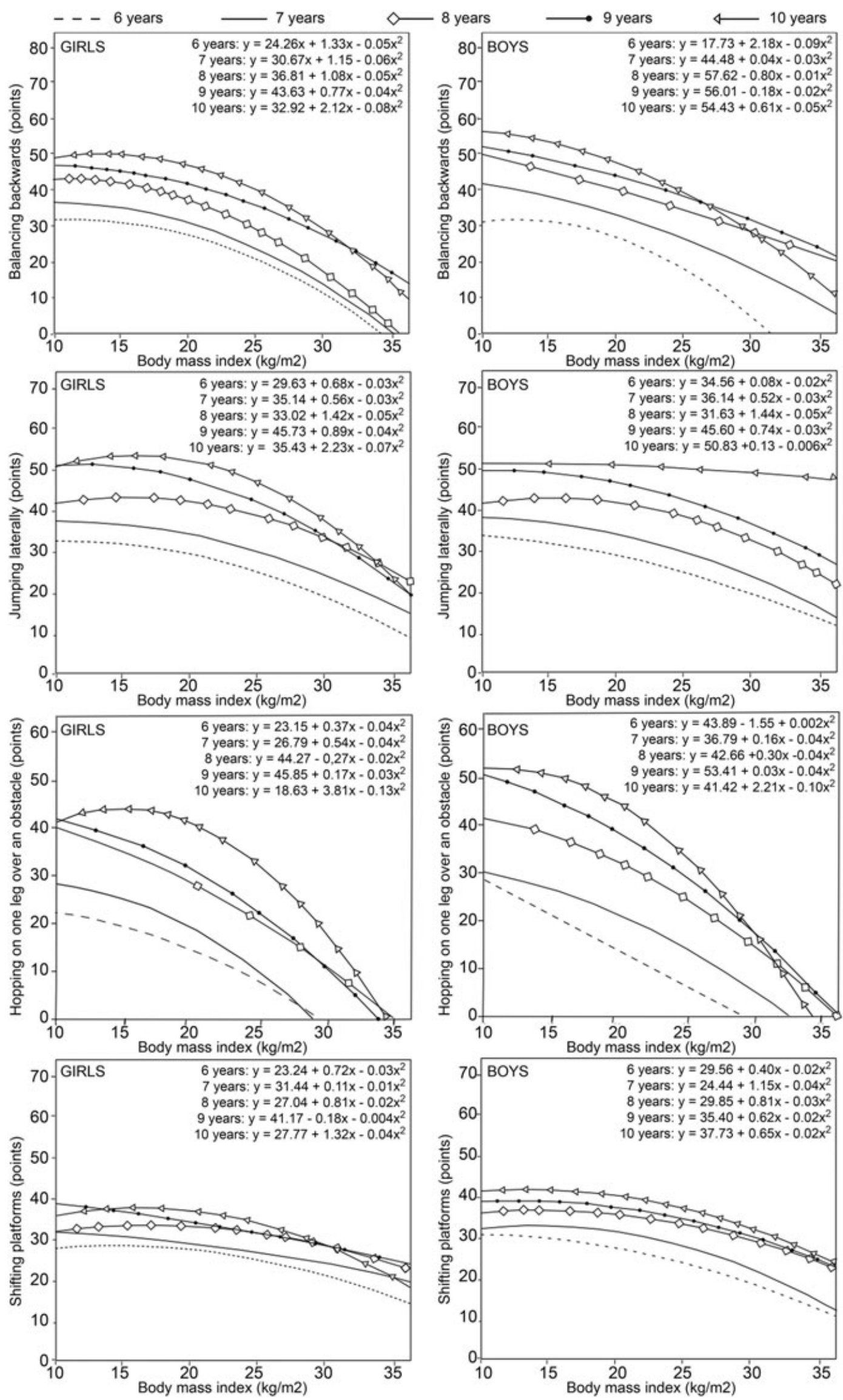

FIGURE 1 Relationship between the body mass index and each motor coordination test item in girls and boys in each age group 


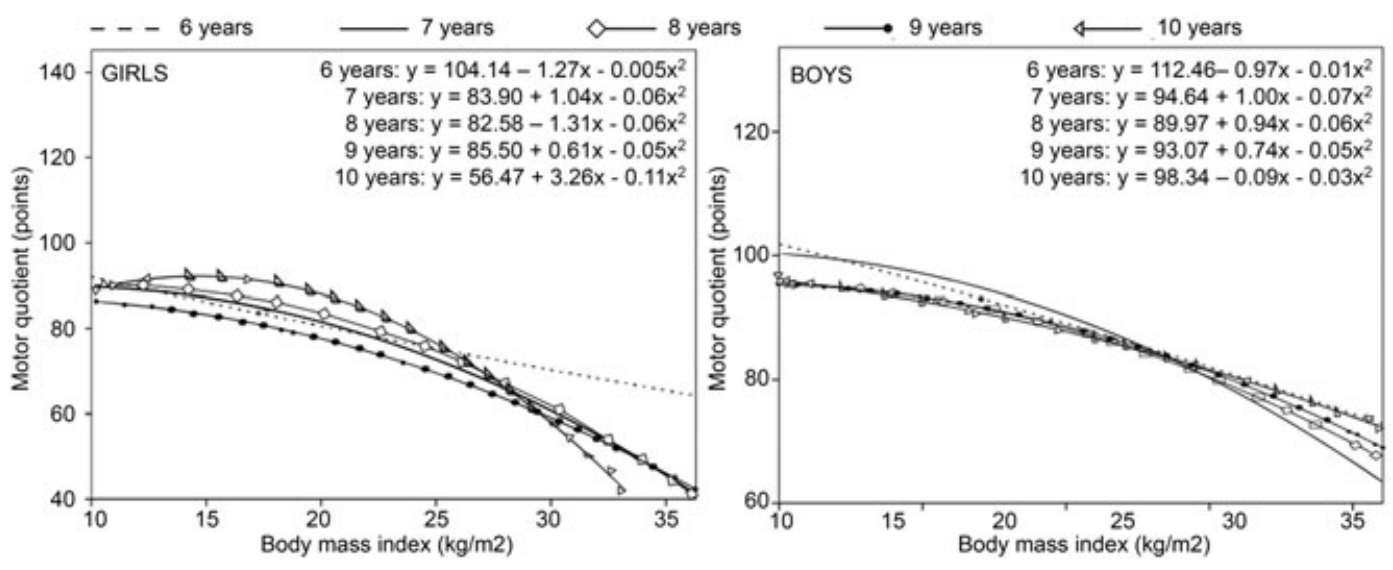

FIGURE 2 Relationship between the body mass index and motor quotient in girls and boys in five age groups

are summarized in Table 2 . The $R^{2}$ values, which indicate the percentage of the variance in each KTK test explained by the model, are low and at best moderate. The explained variance is similar in girls and boys and varies from $0 \%$ to $5 \%$ for jumping laterally, from $1 \%$ to $8 \%$ for shifting platforms, from $3 \%$ to $11 \%$ for balancing backwards, and from $7 \%$ to $23 \%$ for hopping on one leg. $R^{2}$ values for the MQ vary between $6 \%$ and $16 \%$ and are similar in both girls and boys.

Distributions of subjects by weight status within each age group of girls and boys are summarized in Table 3 . Overall, about $5 \%$ of the children are classified as thin, whereas $31 \%$ are classified as overweight or obese. Differences among weight status groups for each KTK test (Table 4) are significant at all ages among children 7 through 10 years with the exception of shifting platforms (girls 8 years) and jumping laterally (boys 10 years). Among 6-year-old children, in contrast, performances on shifting platforms do not differ significantly among weight status groups of girls and boys, whereas performances on balancing backwards and jumping laterally do not differ among weight status groups of boys. The comparisons, of course, should be tempered by the relatively small number of children classified as thin (Table 3). Nevertheless, the trend across weight status categories in each sex is generally similar to the regressions (Figure 1). Performance differences between thin and normal weight children are generally small, and performances are, on average, better than those of overweight and obese children for the KTK tests.

Corresponding statistics for the $\mathrm{MQ}$ of children by weight status categories are also summarized in Table 4. Overall differences among each age group of girls and boys are significant. Among girls, mean MQs show the following gradient at 6 and 7 years: thin $=$ normal weight $>$ overweight $>$ obese; the gradient for girls is modified somewhat at 8, 9, and 10 years: thin < normal weight > overweight > obese. Among boys, the gradient at 6 years is as follows: thin $>$ normal weight > overweight > obese, and is slightly modified at 7 and 9 years: thin $=$ normal weight $>$ overweight $>$ obese, and at 8 and 10 years: thin $<$ normal weight $>$ overweight $>$ obese.

\section{4 | DISCUSSION}

Non-linear relationships between the BMI and $\mathrm{MC}$ were considered in a cross-sectional sample of Portuguese children 6-10 years of age.

TABLE 2 Multiple correlations $(R)$ and common variance $\left(R^{2}\right)$ for each quadratic regression model, in girls and boys by age group. Sample sizes are as in Table 1

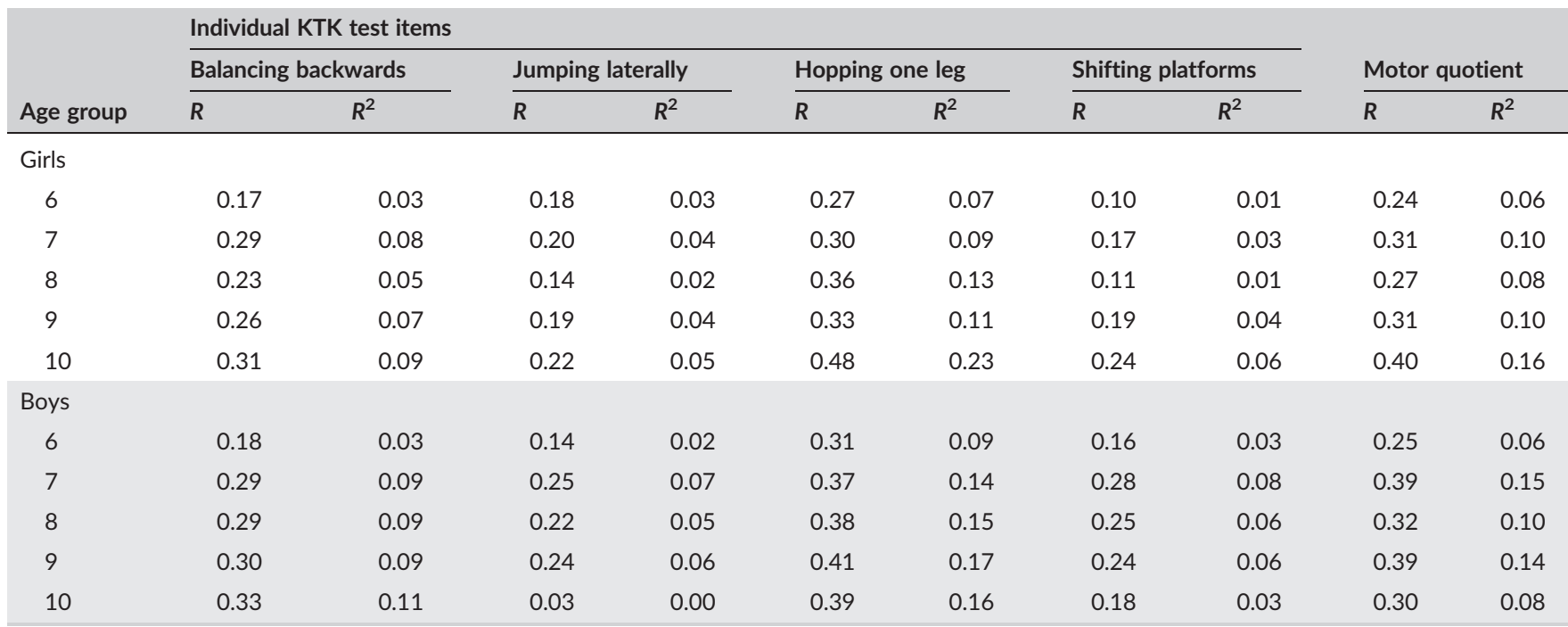

Note. KTK = Körperkoordinationstest für Kinder; $R=$ correlation coefficient; $R^{2}=$ coefficient of determination. 
TABLE 3 Distributions (frequencies [f] and percentages [\%]) of girls and boys by weight status with age groups

\begin{tabular}{|c|c|c|c|c|c|c|c|c|c|}
\hline \multirow[b]{3}{*}{ Age group } & \multirow[b]{3}{*}{$n$} & \multicolumn{8}{|c|}{ Weight status } \\
\hline & & \multicolumn{2}{|c|}{ Thin } & \multicolumn{2}{|c|}{ Normal } & \multicolumn{2}{|c|}{ Overweight } & \multicolumn{2}{|c|}{ Obese } \\
\hline & & $f$ & $\%$ & $f$ & $\%$ & $f$ & $\%$ & $f$ & $\%$ \\
\hline \multicolumn{10}{|l|}{ Girls } \\
\hline 6 & 269 & 7 & 3 & 151 & 58 & 70 & 26 & 35 & 13 \\
\hline 7 & 430 & 12 & 3 & 275 & 64 & 85 & 20 & 58 & 13 \\
\hline 8 & 427 & 12 & 3 & 283 & 66 & 81 & 19 & 51 & 12 \\
\hline 9 & 459 & 19 & 4 & 270 & 59 & 120 & 26 & 50 & 11 \\
\hline 10 & 241 & 7 & 3 & 158 & 66 & 48 & 20 & 28 & 12 \\
\hline \multicolumn{10}{|l|}{ Boys } \\
\hline 6 & 286 & 13 & 5 & 197 & 69 & 46 & 16 & 30 & 10 \\
\hline 7 & 452 & 12 & 3 & 316 & 70 & 66 & 15 & 58 & 13 \\
\hline 8 & 464 & 14 & 3 & 309 & 67 & 83 & 18 & 58 & 13 \\
\hline 9 & 429 & 15 & 3 & 288 & 67 & 77 & 18 & 49 & 11 \\
\hline 10 & 281 & 10 & 4 & 198 & 70 & 50 & 18 & 23 & 8 \\
\hline
\end{tabular}

Relative to IOTF criteria, 31\% of the sample was overweight or obese, which was consistent with data for Portuguese children of about the same age, 31.5\% (Padez, Fernandes, Mourão, Moreira, \& Rosado, 2004). In contrast, only $3 \%$ to $5 \%$ of the sample was classified as thin.

The MQs of the Azorean children did not increase with age, contrary to expectations. Nine- and 10-year-old children of both sexes had, on average, a lower MQ than younger children. The MQ is sexspecific and adjusted for age and is based on the reference sample of German children upon whom the KTK test was developed. In contrast, some evidence has indicated an increase in the MQ with age, but the direction and significance of the differences between age groups were variable (D'hondt et al., 2013).

The negative influence of excess weight, specifically in the form of obesity, on the MC, motor performance, and physical fitness of youth is well established. The literature has typically compared overweight and obese children with normal weight children (Cruz, Sequeira, Gomes, Pinto, \& Marques, 2011; D'hondt et al., 2011; Gonzalez-Suarez et al., 2013; Joshi, Bryan, \& Howat, 2012; Lopes et al., 2012; Lopes, Stodden, \& Rodrigues, 2014; Rodrigues, Stodden, \& Lopes, 2016; Vandendriessche et al., 2011). Consistent with the literature, overweight and obese Azorean children generally possessed lower MQs than this and normal weight children.

In contrast, variation in MC, motor performance, and fitness across the spectrum of BMls in samples of youth has received less attention. Results of quadratic regressions for the MQ in Azorean children 6 to 10 years were generally consistent with observations for an index of fitness based on four tests in four age groups of Taiwanese youth (9-10, 11-12, 13-15, and 16-18 years). The quadratic relationship between the BMI and the index of fitness index was apparent in girls of all ages and in boys $<13$ years of age; results, however, were variable among boys $>13$ years (Huang \& Malina, 2007).

Regressions for individual fitness items among Taiwanese youth varied somewhat with age and sex, but higher BMls were associated with poorer performances on each test (Huang \& Malina, 2010). With few exceptions, the observations in Azorean children 6-10 years showed generally similar results for individual KTK tests in both sexes.
The results for children 8 to 10 years suggested, in general, an inverted parabolic relationship between individual coordination tests and the $\mathrm{BMI}$, that is, a negative influence of a low and especially a high BMI on each MC test; the range of BMls associated with better MC scores also showed a parabolic relationship. On the other hand, the relationship appeared to be more linear among children 6 to 7 years so that children with higher BMI had lower performances in the MC tests.

Corresponding studies of motor performance and fitness of children across the range of BMls from thinness to obesity are limited. Nevertheless, relationships between the BMI and indicators of fitness were generally curvilinear among youth 12-15 years (Bovet et al., 2007) and young adults (Sekulić et al., 2005; Welon, Jurynec, \& W, Ś., 1988).

Observations for several physical fitness items among Spanish adolescents 13-18 years classified as underweight, normal weight, and overweight/obese (Artero et al., 2010) were generally consistent with those for $\mathrm{MC}$ among Azorean children. Underweight and overweight/obese Spanish adolescents had lower physical fitness scores compared with normal weight youth in fitness tests requiring the projection of the body through space (20-m shuttle run, standing long jump, and $4 \times 10$ shuttle run) or support of the body off of the ground (bent arm hang); lowest fitness performances were especially apparent in overweight/obese youth. On the other hand, overweight and obese adolescents performed better in grip strength (Artero et al., 2010).

Lower levels of physical activity and reduced performances on health-related physical fitness tests were observed in underweight and obese compared with normal weight Spanish youth 13-18 years (Artero et al., 2010). Overall, underweight (thin) youth had lower physical fitness scores than normal weight youth, but both thin and normal weight youth generally performed better than overweight/obese youth in fitness tests requiring projection of the body through space (20-m shuttle run, standing long jump, and $4 \times 10$ shuttle run). Two other fitness tests presented exceptions to this pattern. Overweight/ obese youth performed better in static grip strength (i.e., does not require movement of the body through space), whereas underweight (thin) youth performed better in the flexed (bent) arm hang which requires the body to be supported off the ground (Artero et al., 2010).

The relationship between the $\mathrm{BMI}$ and motor tasks thus depends, in part, on whether the task requires the movement or projection of body mass through space or support of the body mass off of the ground. Overweight/obesity is not a negative factor in the performance of some physical fitness tasks, specifically those that do not require the movement or projection of body mass through space. However, excess body mass exerts a negative influence on tasks where the body is moved or projected through space, as in runs and jumps, or the lifting and supporting of the body off the ground, as in pull-ups and the flexed arm hang (Malina, Bouchard, \& Bar-Or, 2004). This factor perhaps influenced the relationship noted between the $\mathrm{BMI}$ and the hopping test of the KTK battery; the BMI explained the highest proportion of variance in this $M C$ test. As such, the negative influence of the BMI on the hopping test also affected, to some extent, the association between the MQ, a composite of the four MC tests, and the BMI.

In contrast, relationships between the BMI and motor performance were somewhat variable among with a history of chronic 


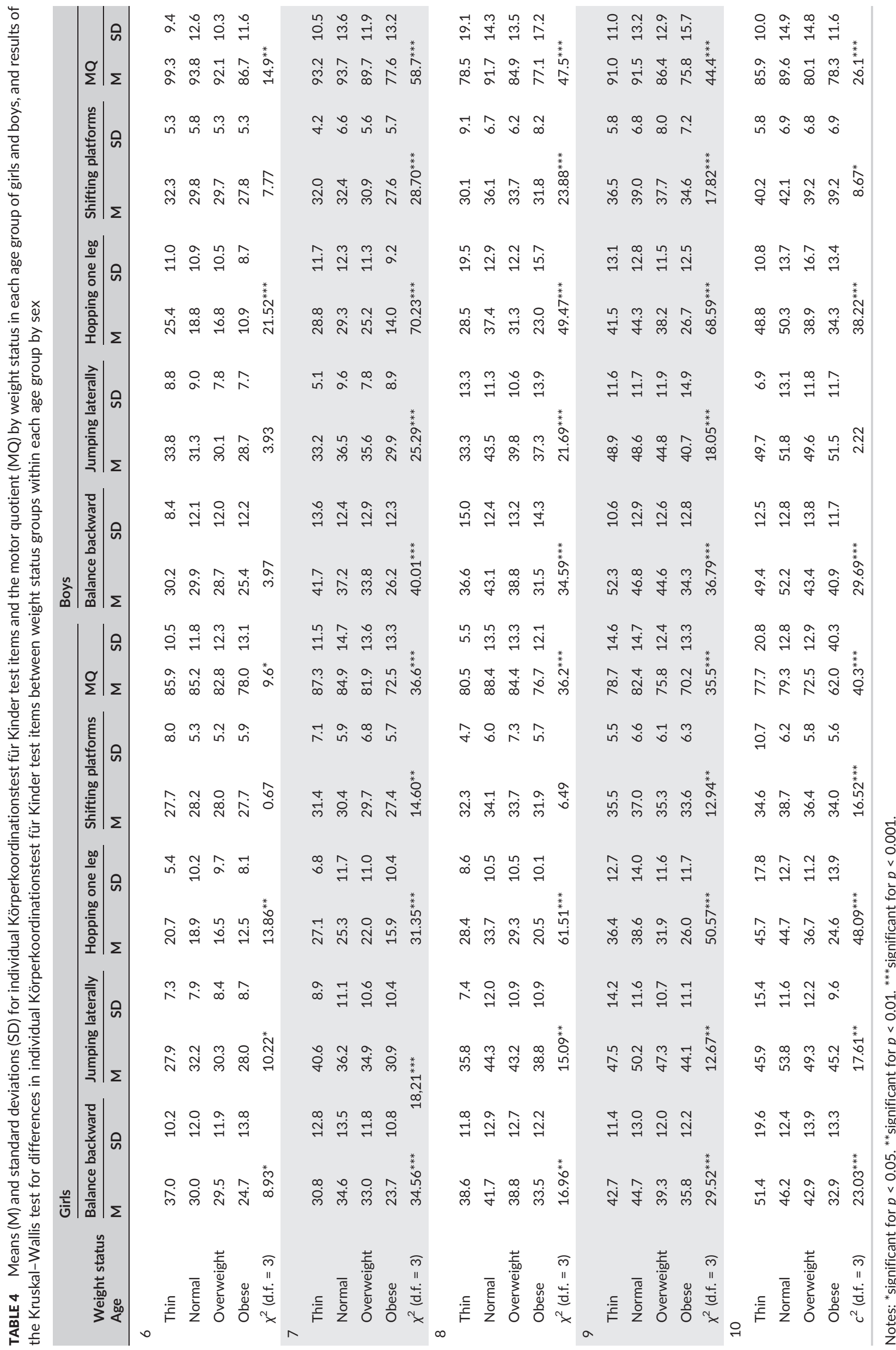


undernutrition compared with better nourished children (Malina, Katzmarzyk, \& Siegel, 1998) and among children who were growth stunted (Malina, Reyes, Tan, \& Little, 2011). By inference, there is need for caution in using the BMI to define weight status in studies of the motor characteristics of children with marginal nutritional histories and perhaps in different cultural contexts.

The use of the quadratic model to evaluate the non-linear association between the BMI and MC may have a potential limitation. The fit of the model was not compared with a more general model (e.g., restricted cubic splines with 4 or 5 d.f.). The lack of an indicator of maturity status may also be a limitation in the analyses. The results are also limited to a sample of children with a good nutritional history. Although specific information on the socioeconomic status of the families of the participants could be an additional limitation, the children were from a region with a high human development index (0.903).

Although a high BMI is widely used as a proxy indicator of excess adiposity, it is not a measure of body composition. The BMI has been complemented with other anthropometric indicators in field studies, for example, waist circumference per se, the waist circumference-toheight ratio, and skinfold thicknesses. The specific dimensions and ratios are widely used in large scale surveys, are inexpensive, and have the advantage of not relying on body weight (Tomiyama, Hunger, Nguyen-Cuu, \& Wells, 2016). However, application of the methods requires experienced technicians and careful attention to and documentation of inter- and intraobserver measurement variability, that is, technical errors of measurement (Malina, Huang, \& Brown, 1995).

Allowing for the limitations, the present study adds to and complements previous research on $\mathrm{MC}$ in children. The results indicated that (a) a high weight-for-height reflected in the BMI had the potential to negatively influence $\mathrm{MC}$; and (b) the BMI had a generally curvilinear relationship in an inverted parabolic shape with $\mathrm{MC}$ in children; the latter observation was more apparent in older (8-10 years) than younger (6-7 years) children. Children with intermediate BMIs tended to have better MC than children with low and high BMls who tended to have poorer MC as measured by the KTK test battery.

\section{ACKNOWLEDGEMENTS}

The first and last authors were supported by the Portuguese Foundation for Science and Technology under Grants DTP/04045/2013; POCI-01-0145-FEDER-006969, and UID/DTP/00617/2013; and by NORTE 2020 under Grant NanoSTIMA: Macro-to-Nano Human Sensing: Towards Integrated Multimodal Health Monitoring and Analytics, NORTE-01-0145-FEDER-000016.

\section{ORCID}

V. P. Lopes (i) http://orcid.org/0000-0003-1599-2180

\section{REFERENCES}

Artero, E. G., España-Romero, V., Ortega, F. B., Jiménez-Pavón, D., Ruiz, J. R., Vicente-Rodríguez, G., ... Castillo, M. J. (2010). Health-related fitness in adolescents: Underweight, and not only overweight, as an influencing factor. The AVENA study. Scandinavian Journal of Medicine \& Science in Sports, 20, 418-427.

Bovet, P., Auguste, R., \& Burdette, H. (2007). Strong inverse association between physical fitness and overweight in adolescents: A large school-based survey. International Journal of Behavioral Nutrition and Physical Activity, 4, 24-31.

Cole, T. J., Bellizzi, M. C., Flegal, K. M., \& Dietz, W. H. (2000). Establishing a standard definition for child overweight and obesity worldwide: International survey. BMJ, 320, 1240-1243.

Cole, T. J., Flegal, K. M., Nicholls, D., \& Jackson, A. A. (2007). Body mass index cut offs to define thinness in children and adolescents: International survey. BMJ, 335, 194-197.

Cruz, C., Sequeira, S., Gomes, H., Pinto, D., \& Marques, A. (2011). Relationship between physical fitness, physical activity and body mass index of adolescents. British Journal of Sports Medicine, 45, A8-A9.

D'hondt, E., Deforche, B., Gentier, I., De Bourdeaudhuij, I., Vaeyens, R., Philippaerts, R., \& Lenoir, M. (2013). A longitudinal analysis of gross motor coordination in overweight and obese children versus normalweight peers. International Journal of Obesity, 37, 61-67.

D'hondt, E., Deforche, B., Vaeyens, R., Vandorpe, B., Vandendriessche, J., Pion, J., ... Lenoir, M. (2011). Gross motor coordination in relation to weight status and age in 5- to 12-year-old boys and girls: A cross-sectional study. International Journal of Pediatric Obesity, 6, e556-e564.

Duncan, M. J., Bryant, E., \& Stodden, D. (2016). Low fundamental movement skill proficiency is associated with high $\mathrm{BMI}$ and body fatness in girls but not boys aged 6-11 years old. Journal of Sports Sciences, 1-7.

Gonzalez-Suarez, C. B., Caralipio, N., Gambito, E., Reyes, J. J., Espino, R. V., \& Macatangay, R. (2013). The association of physical fitness with body mass index and waist circumference in Filipino preadolescents. AsiaPacific Journal of Public Health, 25, 74-83.

Hay, J. A., Hawes, R., \& Faught, B. E. (2004). Evaluation of a screening instrument for developmental coordination disorder. Journal of Adolescent Health, 34, 308-313.

He, Q.-Q., Wong, T.-W., Du, L., Jiang, Z.-Q., Yu, T.-S. I., Qiu, H., ... Wu, J.-G. (2011). Physical activity, cardiorespiratory fitness, and obesity among Chinese children. Preventive Medicine, 52, 109-113.

Huang, Y.-C., \& Malina, R. M. (2007). BMI and health-related physical fitness in Taiwanese youth 9-18 years. Medicine and Science in Sports and Exercise, 39, 701-708.

Huang, Y.-C., \& Malina, R. M. (2010). Body mass index and individual physical fitness tests in Taiwanese youth aged 9-18 years. International Journal of Pediatric Obesity, 5, 404-411.

Joshi, P., Bryan, C., \& Howat, H. (2012). Relationship of body mass index and fitness levels among schoolchildren. The Journal of Strength \& Conditioning Research, 26, 1006-1014.

Kiphard, E. J., \& Schilling, F. (1974). Korperkoordinationstest fur kinder [Body cooordination test for children]. Weiheim: Beltz Test GmbH.

Kiphard, E. J., \& Schilling, F. (2007). Körperkoordinationstest fur kinder [Body cooordination test for children]. Beltz Test $\mathrm{GmbH}$ : Weinheim.

Lopes, V. P., Cossio-Bolaños, M., Gómez-Campos, R., De Arruda, M., Hespanhol, J. E., \& Rodrigues, L. P. (2017). Linear and nonlinear relationships between body mass index and physical fitness in Brazilian children and adolescents. American Journal of Human Biology, 29, e23035.

Lopes, V. P., Stodden, D. F., Bianchi, M. M., Maia, J. a. R., \& Rodrigues, L. P. (2012). Correlation between BMI and motor coordination in children. Journal of Science and Medicine in Sport, 15, 38-43.

Lopes, V. P., Stodden, D. F., \& Rodrigues, L. P. (2014). Weight status is associated with cross-sectional trajectories of motor co-ordination across childhood. Child: Care, Health and Development, 40, 891-899.

Maia, J. a. R. \& lopes V.P. (2007) Crescimento e desenvolvimento de crianças e jovens açorianos. $\mathrm{O}$ que os pais, professores, pediatras e nutricionistas gostariam saber (Growth and development of Azorean children and young people. What parents, teachers, pediatricians, and nutritionists should know), Faculdade de Ciências do Desporto e de Educação Física da Universidade do Porto e Direcção regional de Educação Física e Desporto da Região Autónoma dos Açores, Porto.

Malina, R. M. (1975). Anthropometric correlates of strength and motor performance. Exercise and Sport Sciences Reviews, 3, 249-274. 
Malina, R. M., Bouchard, C., \& Bar-Or, O. (2004). Growth, Maturation and Physical Activity. Champaign: Human Kintetics.

Malina, R. M., Huang, Y. C., \& Brown, K. H. (1995). Subcutaneous adipose tissue distribution in adolescent girls of four ethnic groups. International Journal of Obesity and Related Metabolism Disordorder, 19, 793-797.

Malina, R. M., Katzmarzyk, P. T., \& Siegel, S. R. (1998). Overnutrition, undernutrition and the body mass index: Implications for strength and motor fitness. In J. Parízková, \& A. P. Hills (Eds.), Physical fitness and nutrition during growth. Medicine sport science (pp. 13-26). City: Karger.

Malina, R. M., Reyes, M. E. P., Tan, S. K., \& Little, B. B. (2011). Physical fitness of normal, stunted and overweight children 6-13 years in Oaxaca, Mexico. European Journal of Clinical Nutrition, 65, 826-834.

Martins, D., Maia, J., Seabra, A., Garganta, R., Lopes, V., Katzmarzyk, P., \& Beunen, G. (2010). Correlates of changes in BMI of children from the Azores islands. International Journal of Obesity, 34, 1487-1493.

Mcgavock, J. M., Torrance, B. D., Mcguire, K. A., Wozny, P. D., \& Lewanczuk, R. Z. (2009). Cardiorespiratory fitness and the risk of overweight in youth: The healthy hearts longitudinal study of cardiometabolic health. Obesity, 17, 1802-1807.

Ng, M., Fleming, T., Robinson, M., Thomson, B., Graetz, N., Margono, C., ... Gakidou, E. (2014). Global, regional, and national prevalence of overweight and obesity in children and adults during 1980-2013: A systematic analysis for the Global Burden of Disease Study 2013. The Lancet, 384, 766-781.

Padez, C., Fernandes, T., Mourão, I., Moreira, P., \& Rosado, V. (2004). Prevalence of overweight and obesity in 7-9-year-old Portuguese children: Trends in body mass index from 1970-2002. American Journal of Human Biology, 16, 670-678.

Rodrigues, L. P., Stodden, D. F., \& Lopes, V. P. (2016). Developmental pathways of change in fitness and motor competence are related to overweight and obesity status at the end of primary school. Journal of Science and Medicine in Sport, 19, 87-92.

Sekulić, D., Zenić, N., \& Marković, G. (2005). Non linear relationships between anthropometric and motor-endurance variables. Collegium Antropologicum, 29, 723-730.

Tomiyama, A. J., Hunger, J. M., Nguyen-Cuu, J., \& Wells, C. (2016). Misclassification of cardiometabolic health when using body mass index categories in NHANES 2005-2012. International Journal of Obesity, 40, 883.

Vandendriessche, J. B., Vandorpe, B., Silva, M. J. C., Vaeyens, R., Lenoir, M., Lefevre, J., \& Philippaerts, R. M. (2011). Multivariate association among morphology, fitness, and motor coordination characteristics in boys age 7 to 11. Pediatric Exercise Science, 23, 504-520.

Welon, Z., Jurynec, R., \& W, Ś. (1988). Cięzar należny mężczyzn (Optimal body weight in men). Materialy i Prace Antropologiczny, 109, 53-71.

World Health Organization (2006). WHO Child Growth Standards: Length/ height-for-age, weight-for-age, weight-for-length, weight-for-height and body mass index-for-age: Methods and development. Geneva: World Health Organization.

World Health Organization (2016). Final report of the Commission on Ending Childhood Obesity. Geneva: World Health Organization.

How to cite this article: Lopes VP, Malina RM, Maia JAR, Rodrigues LP. Body mass index and motor coordination: Nonlinear relationships in children 6-10 years. Child Care Health Dev. 2018;1-9. https://doi.org/10.1111/cch.12557 